\title{
Project Development in Mechanical Drawing Curriculum
}

\author{
Xu Hubo* , Liu Lihua, Zhang Di, Chen Zhilan \\ College of mechanical and electrical engineering \\ Shanghai Jianqiao University \\ Shanghai, China \\ E-mail: hubo_xu@126.com \\ * Corresponding Author
}

\begin{abstract}
The purpose of this paper is to transform the center from curriculum content to curriculum structure in mechanical drawing course through the development of project curriculum. During the progress, the students majoring in mechanical design manufacture and automation could master assistant application of threedimension modeling software, such as Solidworks (SW) software. Then, the contradictory relationship on the joint between cultivation in higher education and enterprise needs will be improved.

The tasks of project course are found by analysis on typical machinery spare parts and assembly from machinery enterprise. The students could master the theoretical knowledge through completing the tasks. Engineering drawing of the tasks, which are the typical machinery spare parts and assembly, is aided through three-dimensional design software for mode. In this process, the relative position of the point, line and surface in the three views is defined. Then the engineering drawings are completed. For students, the application of three-dimensional design software is mastered, their space imagination ability is improved, the interest of the course study is increased, so that, the drawing of engineering drawing is more accurate.
\end{abstract}

Keywords- Development ; Mechanical Drawing; Solidworks; Higher Education; Enterprise Needs

\section{INTRODUCTION}

Mechanical Drawing is a basic course of mechanical and electrical engineering, especially in mechanical design manufacture and automation. In addition, it is an elective course for follow-up professional courses. With the development of China's manufacturing industry, the requirements of relevant enterprises to the application of computer-aided design and manufacturing capacity are higher and higher. If the students can use CAD software for structure, process analysis, simulation of mechanical parts skillfully. Moreover, if they are able to draw an engineering drawing meeting the national standard are important symbols of a mechanical engineer. At the same time, the course is the key construction course of Shanghai. Therefore, it is important to explore the teaching methods and establish the system of the teaching for application-oriented technology undergraduate students.

\section{NECESSITIES OF PROJECT DEVELOPMENT}

\section{A. Analysis on Traditional Teaching Method of Mechanical Drawing Course}

For a long time, the engineering drawing course in most of higher education institutions with engineering specialties, which is based on the Soviet Union teaching mode, namely "transfer and acceptance". Because the teaching method guarantee the normal order of the course, the adverse consequences are also obvious. There are three points as below: (1) Due to individual differences in students, some of them have a hard to understand and accept the same teaching process. (2) Under the influence of this kind of teaching mode, students can easily form a single-structured, unalterable personality. Meanwhile, the development of creative and analytical students is limited. (3) The reform of the teaching content has become very cautious, and the teaching content is obsolete. This is mainly caused by the core task of teaching should be the course structure but the content [1]. So that, it causes disconnect between school education and the need of society to the engineering technology professional talented person.

The courses arrangement of the applied technology university must be in line with the development of enterprise. Otherwise, students lack the ability to translate theory into practice, and the professional quality. Therefore, it is necessary to adjust the courses arrangement and teaching method, explore one course teaching system that can solve the traditional teaching methods with many drawbacks. The engineering practical needs will be met.

\section{B. Analysis on Project Curriculum Development of Mechanical Drawing Course}

In teaching practices, there are many doubts about the general adaptability of the project curriculum. The concerns mainly derived from three aspects: (1) Whether the project curriculum can carry all theoretical knowledge; (2) Whether the project curriculum can accumulate the potential of sustainable development for students; (3) Whether the project curriculum is suitable for Higher Vocational Education. On this three issues, $\mathrm{Xu}$ (2009) pointed out that the curriculum reform of higher vocational education is not only feasible but also necessary, in addition to some of the theoretical knowledge as the goal of the course ${ }^{[2]}$. 
A number of studies have focused on the application of the mechanical drawing course reform in higher vocational education ${ }^{[3-10]}$. These studies generally believe that the project teaching method in accordance with the outside to the inside and layer-by-layer in depth learning ideas of mechanical drawing course. It can reflect the level and practicality of mechanical drawing course. Meanwhile, knowledge and skills of mechanical drawing are easy to learn for higher vocational students. However, due to many universities are application and technology undergraduate colleges. Learning based and abilities Students in the kind of colleges are better than higher vocational colleges'. At the same time, they have their own characteristics: emphasizing individuality, not willing to follow the beaten track and passive learning, having strong curiosity and the spirit of exploration. In addition, the method is applied only a part of teaching links in above researches [3]. There is not turn the focus of the project course to the setting of the course. This is likely to make it a mere formality ${ }^{[2]}$. Therefore, it cannot simply copy from the project teaching achievement of the above research report. Nevertheless, the contraction of project course on mechanical drawing should consider the characteristics of students in application and technology undergraduate colleges and the running condition

\section{PROJECT DEVELOPMENT APPROACH OF MECHANICAL DRAWING COURSE}

\section{Overall Planning From the Analysis of Job to the Structure of Project Course}

Before the structure design of project course, the job analysis needs to be completed firstly. It is understood comprehensively that requirements of the graduate employment position on the ability of the mechanical drawing. Moreover, the pertinence of the project design is guaranteed. Through job analysis, the study found: In the process of implementation of the project, technical personnel are to face the engineering drawing. Therefore, the engineering drawing is choosing as the first part of project course content. In order to make the students have a complete concept from the parts to the assembly, we have chosen the typical "gear oil pump assembly" to arrange the contents of the course. Gear oil pump assembly body involves the shaft, disc type and box type parts. The typical engineering parts include shaft type parts, disc type parts, box type parts and fork frame parts. Therefore, the study added the fork frame parts. In order to combine the theory and practice, the typical four kinds parts and assembly is choose as the open wire, and the classic subject knowledge is choose as hidden lines (Fig. 1).
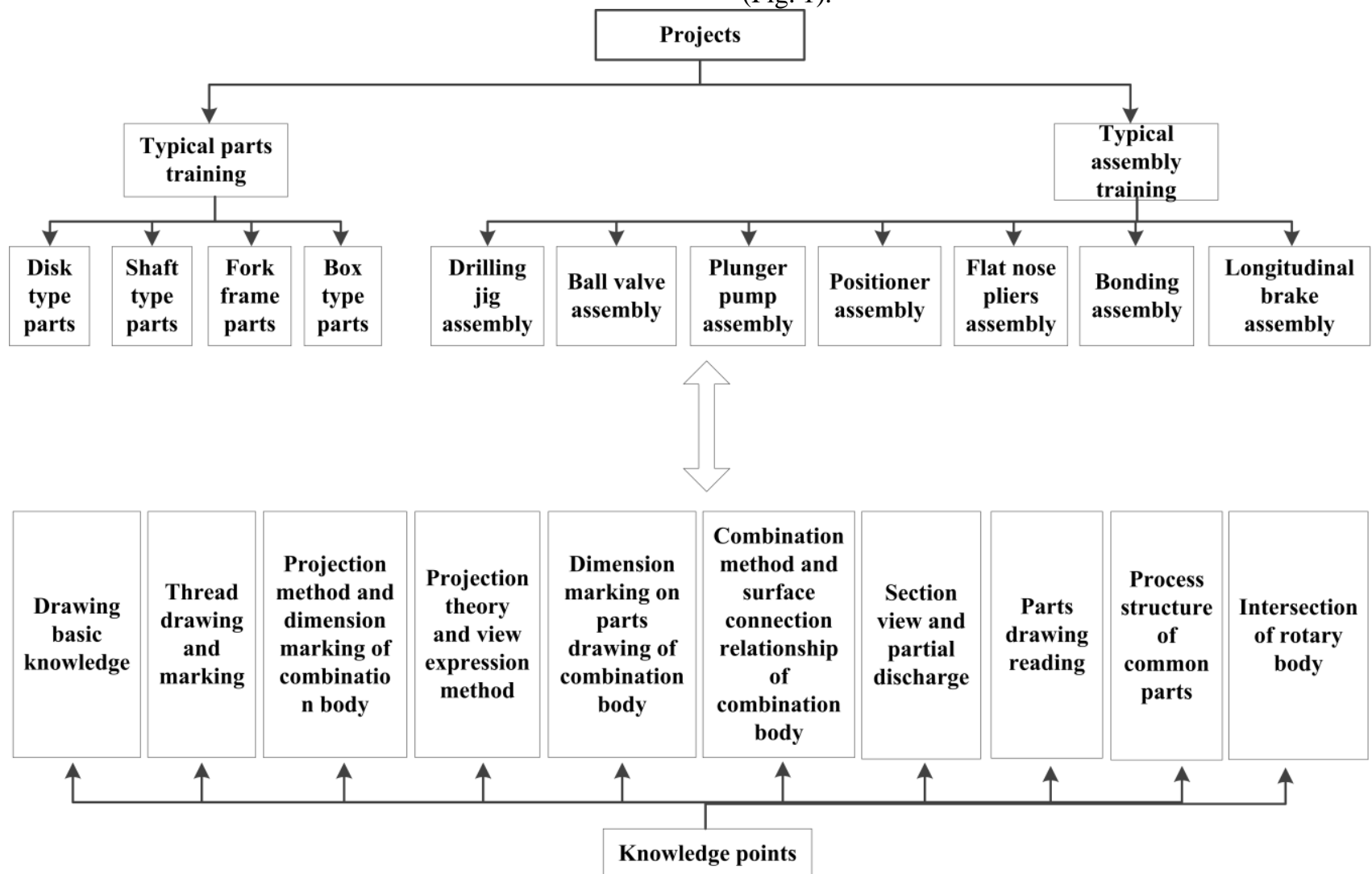

Figure 1. Project Content Planning of Mechanical Drawing

\section{Project Design}

Shaft type parts are executed firstly during the process of project implementation. Disc type, fork frame, box type, and the assembly drawing and reading are executed in the sequence according to the difficulty. Each project is constructed according to "Theory and Practice Integration". That is "Work assignment to "Sources of view and technical requirements exploration" to "Application of classical projection 
theory and related knowledge". The construction of the project is in line with the cognitive law of the students

\section{E. Internal Structure Design of the Project}

In order to facilitate the implementation of the project, the research set up several modules under the project. The structures of modules are similar to the projects'. The first appearances are the specific tasks. The relevant practical knowledge, the theoretical knowledge, the extended knowledge, the evaluation of practice and learning outcomes are to learned or completed in sequence. It is fully reflected that curriculum idea of "working process based" and the rules in education from concrete to abstract and then to concrete. Related practical knowledge is the important step. It mainly includes technical standard, technical knowledge and judgment knowledge, mainly solves the problem of "What" and "How". The main effect of related technology thorny knowledge for students is to promote the understanding of practical knowledge. Furthermore, the elastic and transferable professional ability of students are promoted to formulate. Expanding knowledge is a supplement to the knowledge of work tasks. In addition, each project has clear evaluation criteria and evaluation method. Figure 2 shows the project module structure.

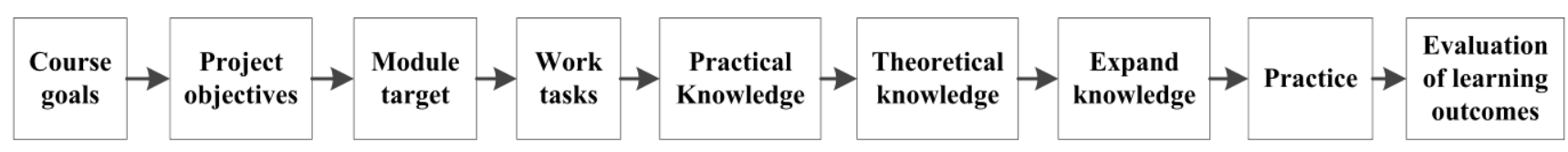

Figure 2. Module Structure Diagram

The choice of the project module should be in accordance with the progressive relationship, in order to make the classical knowledge well in modules. The module cannot oversize when the beginning, and 2-4 periods are suitable. It is easy for students to get the results of the stage; there is a sense of accomplishment.
For example, the module of "Drawing and reading of shaft parts" is set as five modules (Fig. 3). Overall, the module is divided into subdivision. However, it is divided into rough that the comprehensive training module of assembly.

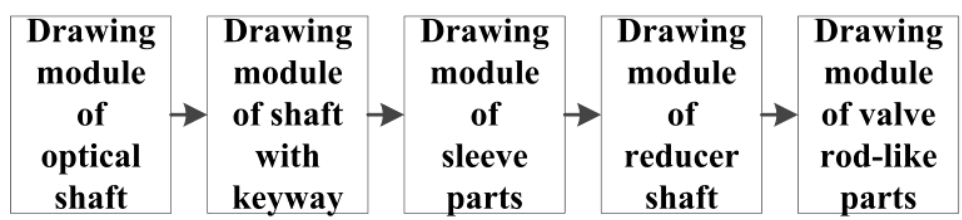

Figure 3. Module Structure Diagram of Shaft Type Parts

\section{F. Concrete Implementation Plan}

The center of project is the work task. Therefore, the project assignment will be prepared and granted in order to make full preparation before class for students. Students are assessed for improving students' learning motivation and competition consciousness after project completion. Solidworks teaching is the main line, supplemented by conventional PPT and writing on the blackboard. The students know how the engineering drawings transform to three-dimensional model in the course of teaching. The space imagination ability of students is improved. Conversely, the space forms of spare parts are obtained by three-dimensional solid model. Then three views are got by the command "Hidden line visible", "Contours", "Master view", "Right view" and "Top view" of Solidworks software.

\section{G. Feasibility Analysis}

Many exploratory studies on the curriculum of project have been carried out in higher vocational education. There are many successful cases, and there are important references for the application of technical undergraduate education. Mechanical drawing course is an important technical basic course. It is necessary to train the application ability of students effectively by the reform of project in the course of teaching. The seamless integration between the school training and business needs will be achieved.

\section{CONCLUSIONS}

The project curriculum in higher vocational education has carried many exploration researches, and there are many successful cases. It has important reference significance to the education of technical applied undergraduate. Mechanical drawing course is an important technical basic course. In order to achieve the school training and enterprise needs seamless integration, it is necessary to cultivate students' application ability by project curriculum reform.

\section{ACKNOWLEDGMENT}

The financial support from the key course of construction project by Shanghai Municipal Education Commission (SZDKC13001) and Specialized Research 
Fond for Shanghai Private University Teacher Development is gratefully acknowledged.

\section{REFERENCES}

[1] Xu Guoqing. 2009. Analysis on the key concepts of current higher vocational curriculum reform, Jiangsu Higher Education, (6): 130-132.

[2] Xu Guoqing. 2008. The Difficulties and Countermeasures in Reform of Higher Vocational Curriculum, Jiangsu Higher Education, (4): 124-126.

[3] Xu Guoqing. 2009. Guide for Curriculum Development of Vocational Education Program, Shanghai: East China Norma University Press, p. 29

[4] Guo Hongxing. 2010. Project Teaching Method Practice in Mechanical Drawing Assembly Teaching, Science and Technology Square, (2): 205-206.

[5] Lu Congxiang \& Li Mingliang . 2014. Discussion on Curriculum reform of Mechanical Drawing and Graphics in
Higher Vocational Colleges, Light Industry Science and Technology, 192(11): 170-171.

[6] Wang Xiaofang. 2012. Reform of Mechanical Drawing Project Teaching, Theory Research, (12): 224-225.

[7] M. Young, The Technical Writer's Handbook. Mill Valley, CA: University Science, 1989.

[8] Li Yinhua \& Jiang qingbin. 2007. Exploration about the Reform of Mechanical Drawing Project Course in Practice, Journal of Wuxi Institute of Technology, 6(5): 71-72.

[9] Tu Xiaohua, Hu Wenwei, Wang Cuifang. 2014. "Mechanical Drawing" Project Oriented Task of Teaching Reform, Jiangxi Chemical Industry, (3): 176-177.

[10] Liu Yan. 2008. Mechanical Drawing Curriculum Exploitation and Teaching Reform through Project Module Carrier and Work Process-oriented Theory, Higher Vocational Education-Journal of Tianjin Vocational Institute, 17(4): 34-37. 